\title{
The International Year of Light 2015 and its impact on educational activities
}

Dan Curticapean, Oliver Vauderwange, Peter Wozniak, Avikarsha Mandal

Dan Curticapean, Oliver Vauderwange, Peter Wozniak, Avikarsha Mandal, "The International Year of Light 2015 and its impact on educational activities," Proc. SPIE 9946, Optics Education and Outreach IV, 994608 (27 September 2016); doi: 10.1117/12.2237954

Event: SPIE Optical Engineering + Applications, 2016, San Diego, California, United States 


\title{
The International Year of Light 2015 and Its Impact on Educational Activities
}

\author{
Dan Curticapean $^{1 *}$, Oliver Vauderwange ${ }^{1}$, Peter Wozniak $^{1}$, Avikarsha Mandal $^{1}$ \\ ${ }^{1}$ Offenburg University, Badstr.24, 77654 Offenburg Germany \\ *dan.curticapean@hs-offenburg.de
}

\begin{abstract}
The International Year of Light and Light-Based Technologies 2015 (IYL 2015) was celebrated around the world. Worldwide activities were organized to highlight the impact of optics and photonics on life, science, economics, arts and culture, and also in education.

With most of our activities at Offenburg University of Applied Sciences (Offenburg/Germany), we reached our own students and the general population of our region:

- $\quad$ University for Children: "The Magic of Light" winter lecture program and "Across the Universe

with Relativity and Quantum Theory" summer lecture program

- "Students Meet Scientists"

- "A Century of General Relativity Theory" lecture program
\end{abstract}

Nevertheless, with some of our activities we also engaged a worldwide audience:

- $\quad$ IYL 2015 art poster collection (Magic of Light and No Football, Just Photonics)

- $\quad$ Smart Interactive Projection

- $\quad$ Twitter Wall

- "Invisible Light"

- $\quad$ Live broadcasting of the total lunar eclipse

- $\quad$ Film Festival Merida Mexico

The authors will highlight recent activities at our university dedicated to promote, celebrate, and create a legacy for the IYL 2015.

Keywords: Education in Optics and Photonics, International Year of Light and Light-Based Technologies

\section{INTRODUCTION}

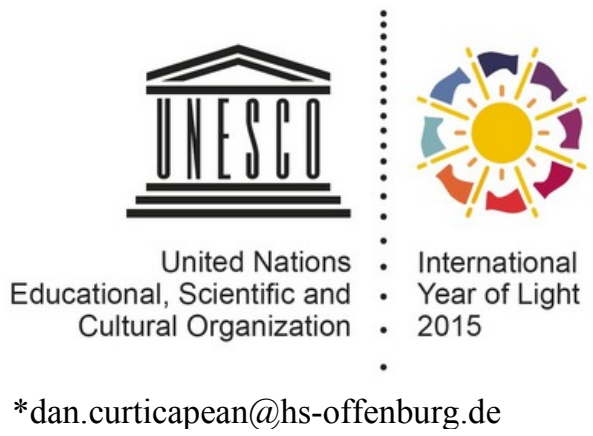

The International Year of Light in 2015 [1] was celebrated in 148 countries worldwide. With more than 5000 distinct tracked events, it turned out to be the most successful "International Year" celebrated by UNESCO [2]. The IYL 2015 website was accessed from 191 countries, and 24 commemorative postage stamps were created. [3]

An important guarantor for its success was an excellent preparation process started several years in advance. The original idea was already born during the IY Astronomy, in 2009, according to Professor John Dudley, Chairman of the IYL 2015 Steering Committee. The special 
achievement of the IYL 2015 is due above all to the efforts of John Dudley and his team of the EPS (European Physical Society).

For us at Offenburg University it was a special pleasure to contribute to the preparations. Our activities dedicated to the IYL 2015 were guided by three major temporal objectives:

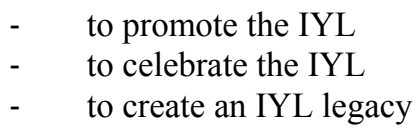

The last aspect - legacy, in the sense of long-term sustainability of the projects - is an especially important one to us. We want to not just cherish the memories of the IYL 2015, but keep its ideas alive. We hope that the spirit of the IYL 2015, and the sparks of curiosity about optics and photonics it has ignited in the young people, will live on through the introduction of an annual "International Day of Light." While its exact date is yet to be determined by UNESCO (as of July 2016), there have been a number of suggestions, including our own proposal for March 14, which already commemorates both Albert Einstein's birthday and the number $\pi$ as "Pi Day" (3/14).

The most important blog contributions from the IYL 2015 were summarized in the publication, Inspired by Light Reflections from the International Year of Light 2015. In three thematic chapters - Culture and Education, People and History, and Science and Technology - the book addresses all fields and aspects related to light. Our own contribution is an article in the Science and Technology chapter, titled "Photonics Is a Player at the 2014 World Cup."

We would like to point out that our projects at Offenburg University dedicated to the IYL2015 were especially meant to engage the young - children aged 8 and up, college-level students and young adults. We were also able to expand on our activities and reach both local and worldwide audiences through different projects, a goal which we will continue to pursue in the future.

\section{ACTIVITIES DEDICATED TO THE IYL 2015 AT OFFENBURG UNIVERSITY}

Projects for the IYL 2015 undertaken at Offenburg University included:

1. IYL 2015 art poster collection, Magic of Light website

- promotion, celebration and legacy

- worldwide availability

2. Art poster "No Football - Just Photonics" Magic of Light website

- promotion, celebration and legacy

- worldwide availability

3. Smart interactive projection

- celebration during the IYL 2015 opening ceremony

- shown in the foyer of the Paris UNESCO building

- worldwide availability

4. University for Children "The Magic of Light"

- winter lecture program

- celebration, regional

5. University for Children "Across the Universe with Relativity and Quantum Theory"

- summer lecture program

- celebration, regional 
6. Twitter wall Munich

- celebration

- International Congress Center at Laser Munich/Germany (June 2015): European Conference on Lasers; Electro-Optics, International Quantum Electronics Conference OSA, EPS, Optical Metrology 2015 SPIE

- worldwide availability

7. Twitter wall Merida

- celebration during the IYL 2015 closing ceremony at Yucatán Convention Center Merida

- worldwide availability

8. A Century of General Relativity Theory

- Lecture evening

- celebration, regional

9. Live broadcasting of the total lunar eclipse 2015

- promotion, celebration and legacy

- worldwide availability

10. Students Meet Scientists

- Google Glass developer and SPIE Fellow Bernard Kress

- celebration and legacy, regional

11. "Invisible Light"

- promotion, celebration and legacy

- worldwide availability

12. Film Festival Merida Mexico

- two Film contributions

- celebration and legacy, Yucatán Convention Center Merida/Mexico

- worldwide availability

\section{3. "MAGIC OF LIGHT" ART POSTER COLLECTION}

As described in earlier papers [4], we prepared a whole poster series dedicated to the IYL 2015, which was one of the most elaborate projects undertaken in this context. It should be pointed out that this was an interdisciplinary project open to anyone, i.e. not just students of physics.

Figure 1 shows a selection of the best works, which were combined on a postcard used for promotional purposes in the run-up to the IYL2015. In a larger poster format, this selection was also exhibited to promote the IYL 2015 at the following venues:

- International Congress Center at Laser Munich/Germany (May 2013): European Conference on Lasers; Electro-Optics, International Quantum Electronics Conference OSA, EPS, Optical Metrology 2013 SPIE

- Education \& Training in Optics \& Photonics in Porto/Portugal (July 2013): OSA, SPIE, EPS Conference

- Optics \& Photonics in San Diego/USA (August 2013): SPIE Conference

- $\quad$ Frontiers in Optics in Orlando/USA (October 2013): OSA Conference

- $\quad$ Allied Arts of Whatcom County in Bellingham, WA/USA (January 2014) [5]-[6]

- Opening Ceremony, UNESCO Headquarters in Paris/France (19-20 January 2015)

The posters can continue to be used to reference the event in the future, thanks to their enormous, worldwide impact factor: By June 2016, we had received a total of ca. 2600 user requests and counted more than 10,000 poster downloads from around the world. It is also worth mentioning that until early 2014, when Googling "International Year of Light" the Magic of Light website came up as the first search result. 


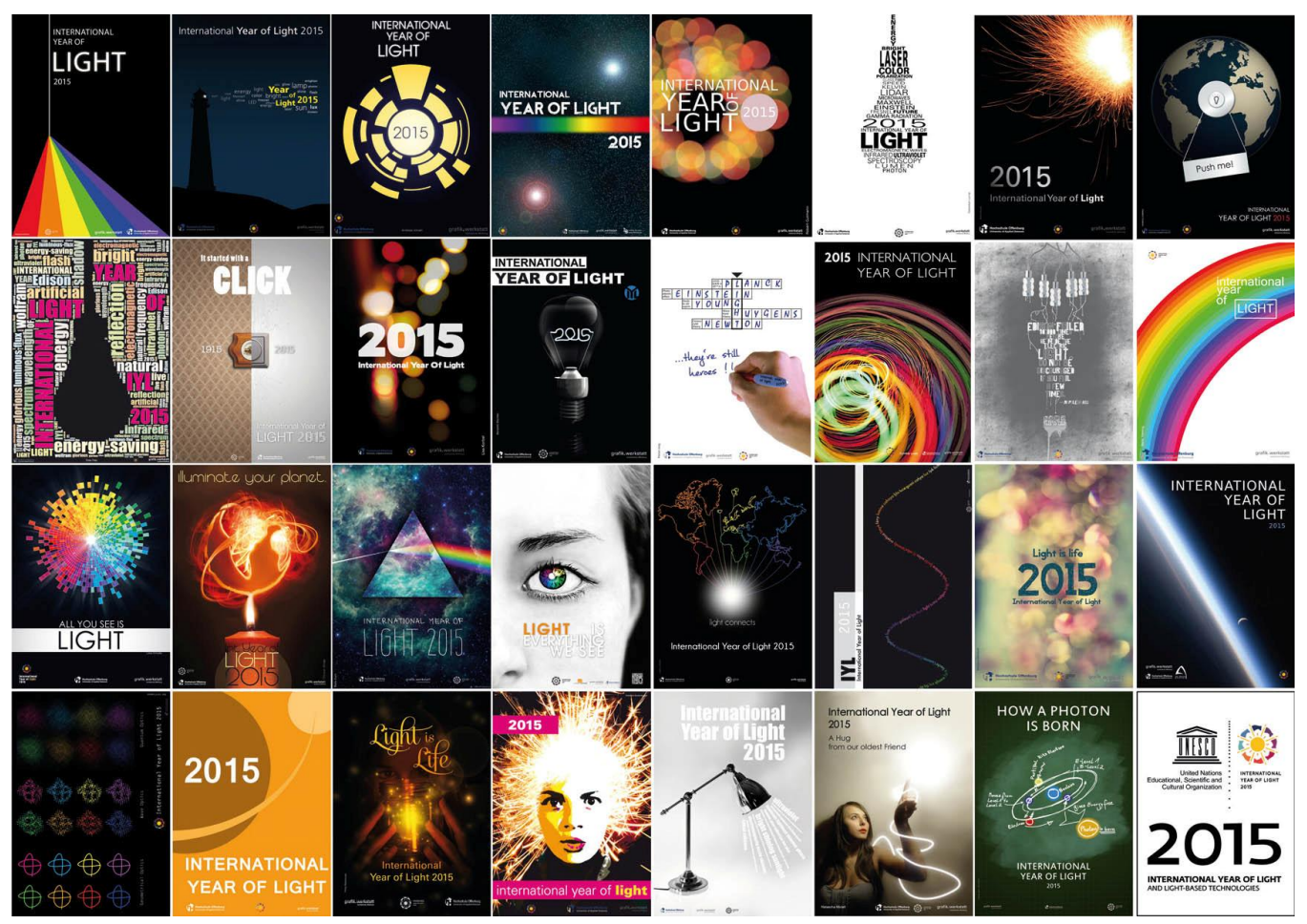

Fig. 1: Artwork poster: Magic of Light; (C) www.Offenburg-University.de/iyl2015

Another poster series, No Football, Just Photonics (Fig.2), also contributed to the success of the project:

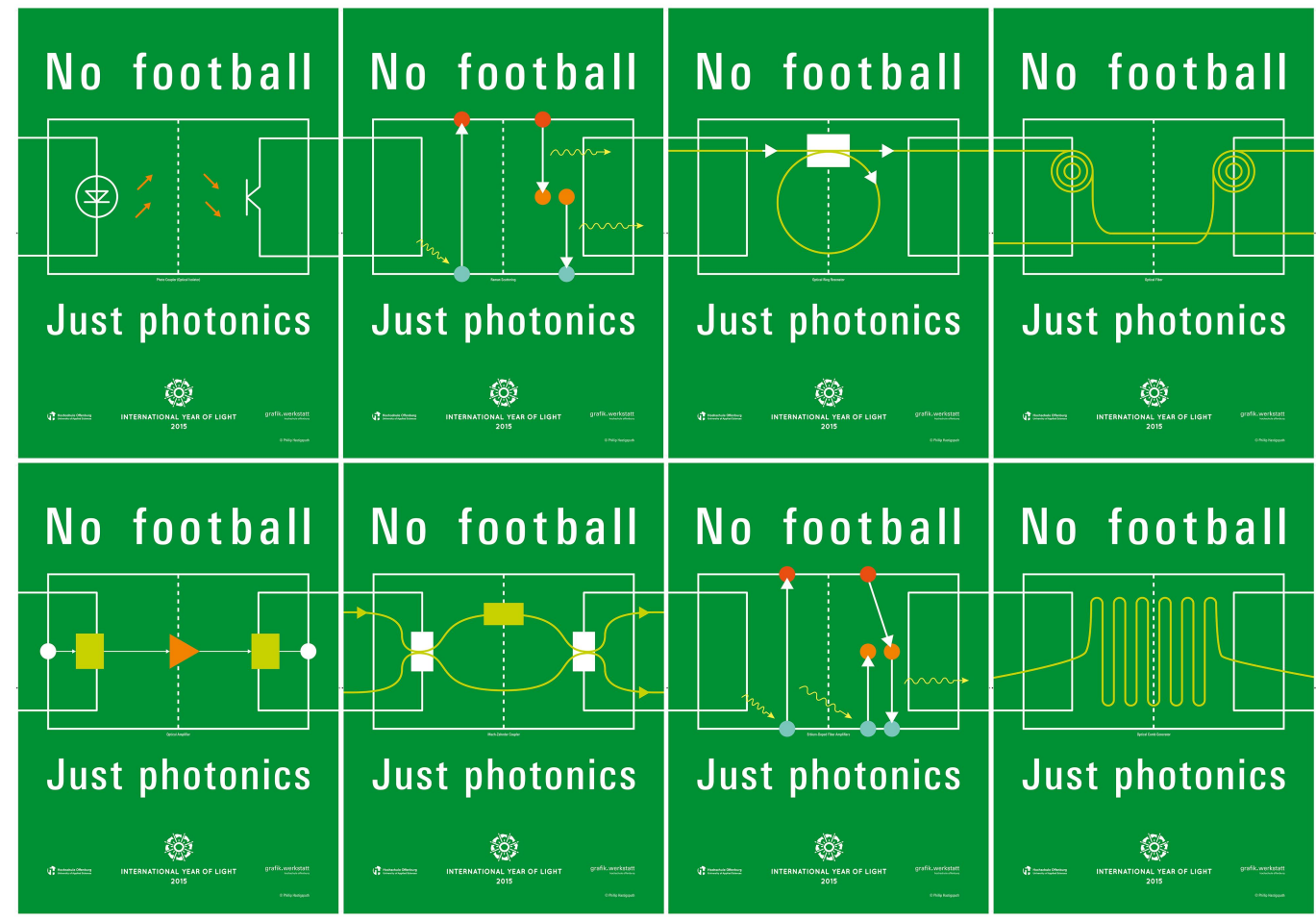

Fig. 2: Artwork poster: No Football, Just Photonics; (C) www.Offenburg-University.de/iyl2015 


\section{A CENTURY OF GENERAL RELATIVITY THEORY}

One of the major milestones of the IYL 2015 was the centennial of Albert Einstein's General Relativity Theory, in which he showed how light is at the center of the very structure of space and time.

It was on 25 November 1915 that Einstein revolutionized the field of physics with the publication of his General Relativity Theory. In recognition of this extraordinary achievement, Offenburg hosted a lecture evening on the exact same day, 100 years later. As a highlight of the IYL2015, the event was well publicized through the local press and attracted a wide audience. Still, the amount of ca. 450 attendees far exceeded our expectations.

As invited speaker, we were delighted to welcome the Director of the German Mathematical Institute from Oberwolfach, Professor Stephan Klaus. This allowed us to draw special attention to "The Race for the General Relativity Theory" between Einstein and David Hilbert. The two other lectures of the evening were

- "Mehr Geometrie wagen" ('dare for more geometry') and

- "Albert Einstein - 100 Jahre Relativitätstheorie"

The speakers managed to not only make the significance of the General Relativity Theory tangible to a broad audience, but also explain its controversial nature and the competition surrounding it at the time of its development. A central aspect were the predictions postulated with the General Relativity Theory - only when one of them was actually proven, through the total solar eclipse of 1919 , did Einstein become the celebrated 'pop star of science' as which we know him today. The seven major predictions Einstein had made regarded the following: [7]

- Perihelion precession of Mercury

- Deflection of light by the Sun

- Gravitational redshift

- Expansion of the universe

- Gravitational radiation and gravitational waves

- Black holes

- Cosmological constant

The lectures were accompanied by many illustrative experiments, including an experiment demonstrating the principle of measuring gravitational waves - the only prediction of Einstein's not yet proven by then, on 25 November 2015. In retrospect, we have been especially happy about this part of the evening, as on 11 February 2016 the LIGO Observatories announced their detection of gravitational waves: They were measured during a collision of two black holes having masses of around 29 and 36 sun masses, which circled around each other and then merged into one black hole of 62 sun masses. In accordance with Einstein's famous equation, $E=\mathrm{mc}^{2}$, the resulting difference of three sun masses was energy emitted in gravitational waves. Thanks to the light, and to laser, we can still measure this fusion today, 1.3 billion years after the fact. With his General Relativity Theory, Einstein had predicted such measurements 100 years earlier. [8] 
Other significant achievements of Einstein's were cited in the lectures as well. Even without the theory of relativity, science historians consider Einstein as one of the most important physicists. To him we also owe the photoelectric cell, laser, the development of plastics, the fields of astrophysics and nuclear physics. Without General Relativity Theory we would not have sharp images on TV and computer screens and no precise GPS navigation tools. In short, without Einstein we would almost certainly not have the living standard we enjoy today.

The only scientist ever to receive a ticker-tape parade in New York City, on 2 April 1921 [9], Einstein once explained to his son Eduard the reason for his fame:

"You see, when a blind beetle crawls over the surface of a curved branch, it doesn't notice that the track it has covered is indeed curved. I was lucky enough to notice what the beetle didn't notice." [10]

Another aspect highlighted during the lecture program was Einstein's achievements as a human being, a pacifist and human-rights activist. To give only a few examples, he was one of the few scientists opposing the First World War; he was the youngest member admitted, on 7 June 1924, to the order of merit Pour le Mérite, but renounced his membership in 1933 [11]; he was offered the presidency of Israel in 1952 [12]; he was co-author of the 1955 Russell-Einstein Manifesto [12] highlighting the dangers posed by nuclear weapons and calling for peaceful resolutions to international conflict, which is widely regarded as the beginning of the peace movement.

\section{INVISIBLE LIGHT}

Today this application could be called "Pokemon Go for Optics and Photonics." The idea first came about two years ago, when a group of students worked on an interactive smartphone app (Fig. 4), as well as on the question what light actually means for us in the context of the IYL2015. On the corresponding website (Fig. 5), http://www.invisible-lightproject.com, users gain insights into various aspects of optics, photonics and other light-related issues, but can also post and share contents on their own. The smartphone app visualizes the information and transmits it to end users in real time. The project was presented in detail in an earlier paper, "Invisible Light" - A global infotainment community based on augmented reality technologies" [13]. This project is also showcased by Wikitude [14] at:

http://www.wikitude.com/showcase/invisible-light-project-wikitude-hs-offenburg-international-year-light-2015/.

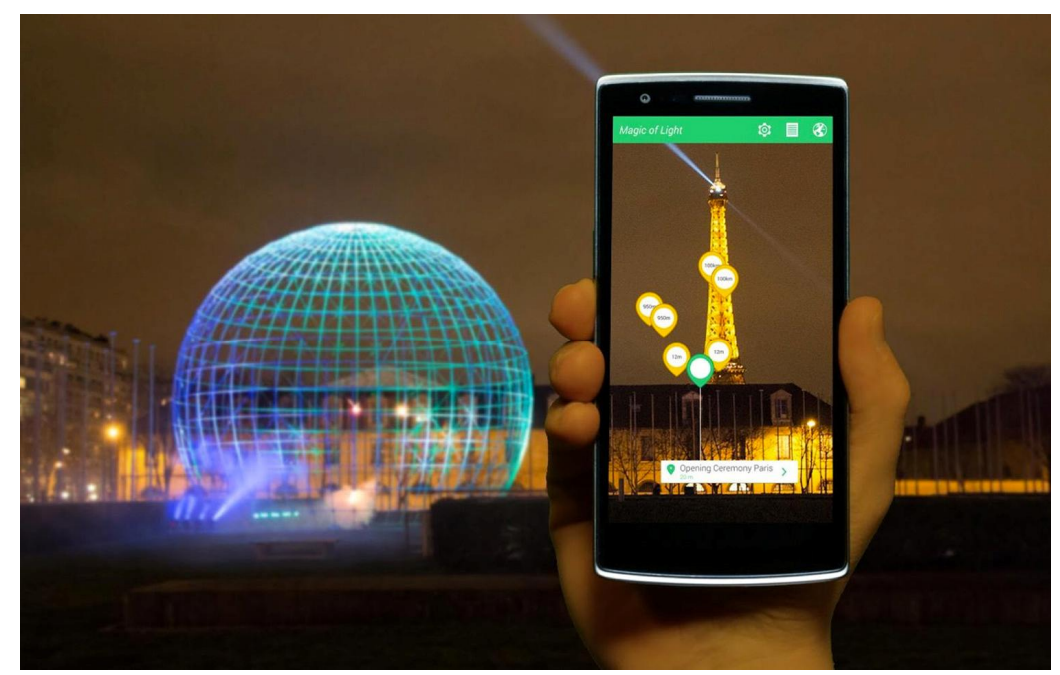

Fig. 4: Invisible Light App 


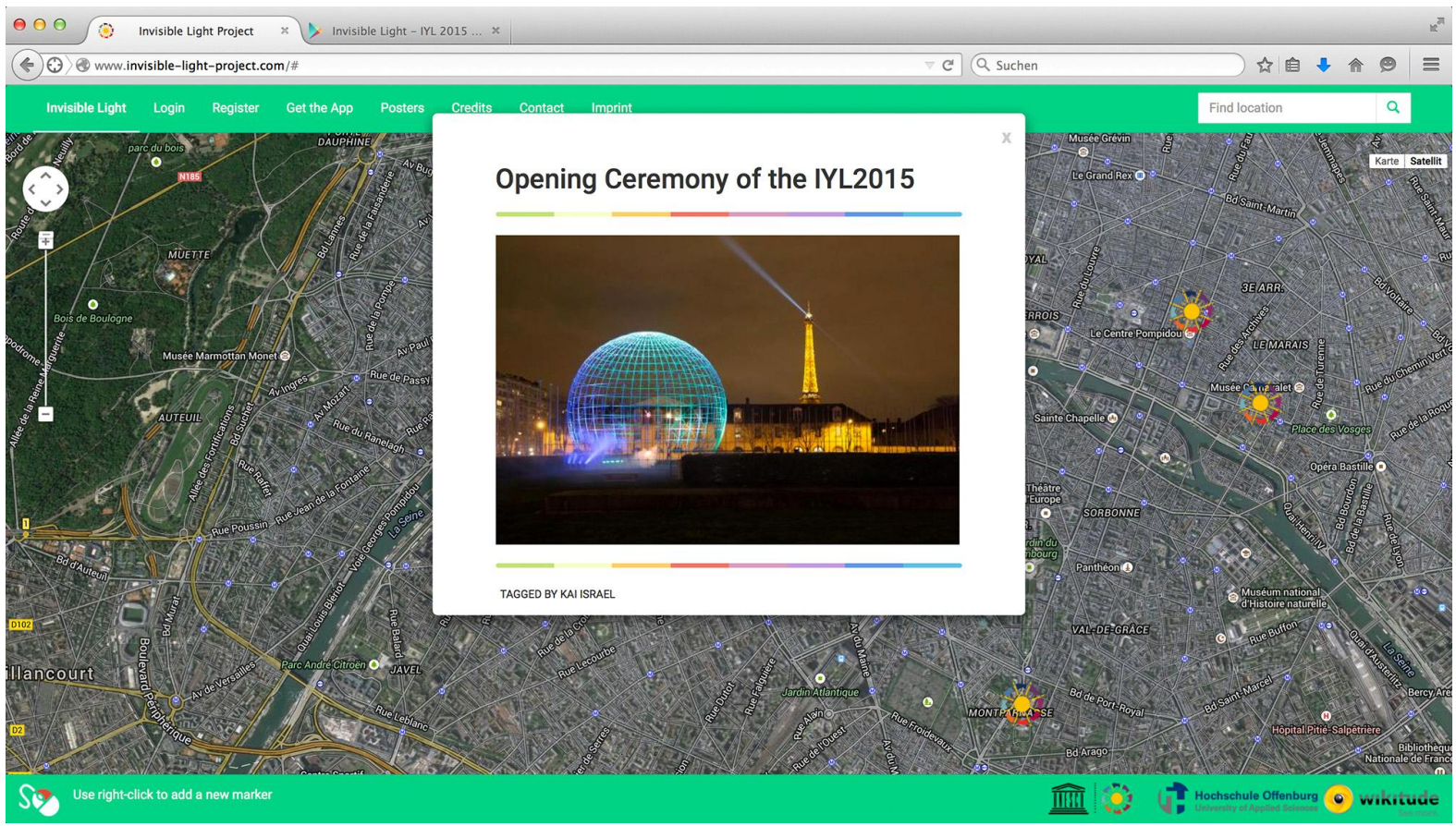

Fig. 5: Invisible Light website with markers for the IYL2015 opening ceremony

\section{LIVE BROADCASTING OF THE TOTAL LUNAR ECLIPSE 2015}

During the IYL 2015, in the early morning hours of September 28, a total lunar eclipse occurred, presenting an excellent opportunity to highlight the IYL at Offenburg University with a live broadcasting event. Starting just after midnight, we reported from astronomical observatories around the world, conducted interviews with scientists and covered a range of other astronomical topics. The live broadcast was viewed by over 70,000 viewers from 143 different countries, totaling more than half a million viewer minutes during four hours of broadcasting. More information and images can be accessed at: www.eclipse-live.com.

We have reported about our experiences in a previous paper, "Astronomical phenomena: Events with high impact factor in teaching Optics and Photonics" [15]-[16]. Furthermore, the iBook "Moonbook" prepared by our students can be downloaded for free [17].

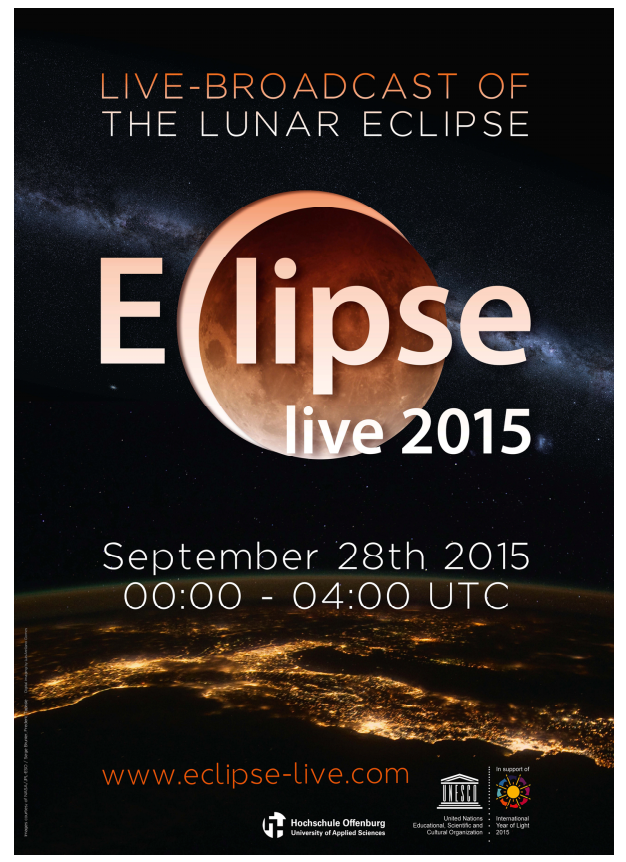

Fig. 6: Poster for the live broadcasting of the total lunar eclipse 2015

(C) Luis Arellano / Offenburg University 


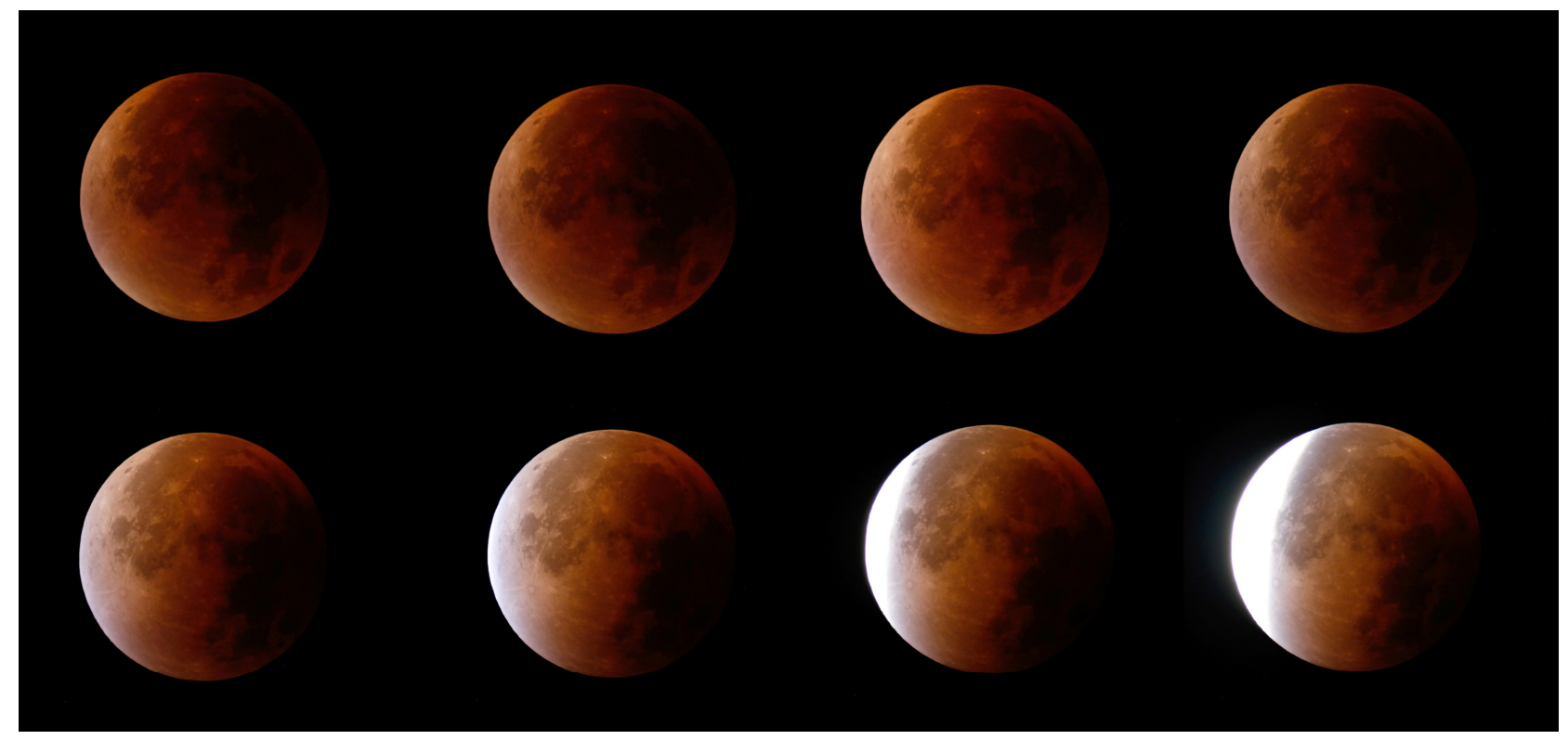

Fig. 7: Total lunar eclipse on September 28, 2015, over Offenburg/Germany (C) Dan Curticapean / Offenburg University

\section{CONCLUSIONS AND PERSPECTIVES}

In sum, we can look back on a dozen projects dedicated to the IYL 2015. They all involved our students, but we also reached the general population in our region, as well as a worldwide audience through our artwork projects, live broadcastings, and the Invisible Light project. We thus majorly contributed to the promotion of the IYL 2015, but also to its legacy, thanks to the sustainability of most of the projects.

I would like to conclude with a tweet from John Dudley, posted at the closing ceremony of the IYL in Merida/Mexico:

"Amazing feeling to see much accomplished during the IYL 2015. A real privilege to be involved with so many great people. Let's keep going!”

\section{ACKNOWLEDGMENT}

The author would like to thank all who supported him in the activities described in this article, especially Professor John Dudley, President of the European Physical Society ("Mister IYL2015"), and Dr. Eugene Arthurs, SPIE CEO; many thanks also to all the students, colleagues at Offenburg University who helped implement all these projects.

\section{REFERENCES:}

[1] United Nations, "International Year of Light and Light-Based Technologies 2015", General Assembly 68/221 resolution adopted by the General Assembly on 20 December 2013 (2013)

[2] Maciej Nalecz, "Preparatory meeting for the Closing Ceremony IYL 2015 Merida Mexico", Director of UNESCO's Division of Science, Policy and Capacity Building Munich 22 June (2015) 
[3] John Dudley, "Lighting the Future of Photonics: The Legacy of the International Year of Light", Photonics Europe, Brussels Hot Topics I, April $8^{\text {th }}$ (2016)

[4] Curticapean, D., "Photonics meets digital art", Optics Education and Outreach III, Proceedings of SPIE, Vol. 9188-21, doi: 10.1117/12.2061861, San Diego/USA (2014)

[5] SPIE, "SPIE to Celebrate Light in Art and Technology at Gallery Show" http://www.prweb.com/releases/2013/12/prweb11449343.htm (2013)

[6] ***, "The Art of Light and Technology",

http://calendar.bellinghamherald.com/bellingham_wa/events/show/368966961-the-art-of-light-and-technology (2013)

[7] Lawrence M. Krauss, "What Einstein got wrong", Scientific American, September (2015)

[8] B. P. Abbott et al., "Observation of Gravitational Waves from a Binary Black Hole Merger (LIGO)"

Scientific Collaboration and Virgo Collaboration) PHYSICAL REVIEW LETTERS, PRL 116, 06110211

February 2016, DOI: 10.1103/PhysRevLett.116.061102 (2016)

[9] Laura Fitzpatrick, "Ticker-Tape Parades", Time http://time.com/3950093/ticker-tape-parades/ Nov. 6 (2009)

[10] Carl Seelig, "Albert Einstein: A Documentary Biography”, Staples Press, (1956)

[11] ***, "Pour le Mérite" Wikipedia, https://de.wikipedia.org/wiki/Pour_le_M\%C3\%A9rite (01 August 2016)

[12] W. Isaacson, "Einstein Genie und Popstar" Bucher Verlag München (2009)

[13] Israel, K., Wozniak, P., Vauderwange, O., Curticapean, D., "Invisible Light" - A global infotainment community based on augmented reality technologies", $13^{\text {th }}$ Education and Training in Optics and Photonics Conference, Bordeaux/France (2015)

[14] Wikitude GmbH, "Invisible Light Project - Wikitude in the International Year of Light 2015", http://www.wikitude.com/showcase/invisible-light-project-wikitude-hs-offenburg-international-year-light2015/. 4 May (2015)

[15] Curticapean, D., "Magic of Light", Proc. SPIE 7783, Optics Education and Outreach, 77830I (31 August 2010); doi: $10.1117 / 12.862847,(2010)$

[16] Curticapean, D., "Astronomical phenomena: events with high impact factor in teaching optics and photonics", Proc. SPIE 9289 12th Education and Training in Optics and Photonics Conference 928909; doi: $\underline{10.1117 / 12.2070281}(2014)$

[17] Cerkovniak, A., Hermanns, D., Nitsche, N., Stöferle, S., Wilke, R., [Moonbook], iBook https://itunes.apple.com/de/artist/anika-cerkowniak/id599570824?mt=11 (2011) 